\title{
VIRTUE EPISTEMOLOGY AND THE GETTIER DILEMMA
}

\author{
Ian M. Church \\ Hillsdale College \\ 33 E. College St. \\ Hillsdale, MI 49242 \\ USA \\ Email: ichurch@hillsdale.edu
}

\section{Forthcoming in Metaphilosophy}

\begin{abstract}
The Gettier dilemma facing reductive analyses of knowledge has not been properly appreciated by virtue epistemologist or even virtue epistemology's most vocal critics. In $\$ 1$, we start by considering how recent critics of virtue epistemology understand the Gettier Problem facing virtue-theoretic accounts of knowledge. I highlight how the dilemma facing virtuetheoretic analyses of knowledge is more general than these critics seem to suggest. In $\$ 2$, I elucidate the worry that the threat facing virtue epistemology is really a dilemma between Gettier counterexamples and radical skepticism. In $\$ 3$, we will consider how some recent virtue epistemologists have tried to viably defuse the Gettier Problem. We will see (i) just how the critiques elucidated in $\$ 1$ have (mis)shaped the dialectic between virtue epistemology and what is required in solving Gettier counterexamples and (ii) how this has led to virtue epistemologists underestimating the widespread insidiousness of Gettier counterexamples.
\end{abstract}

KEY WORDS: The Gettier Problem; Reductive Analysis of Knowledge; Virtue Epistemology

Epistemology is on the move. Ever since 1963 when Edmund Gettier challenged the sufficiency of the standard analysis of knowledge with a series of counterexamples, all attempts to defend it have been shown either to lead to further Gettier-style counterexamples or to produce analyses of knowledge that are not viable. And as such, there is a growing movement in contemporary epistemology away from reductive accounts of knowledge toward alternative, non-reductive models. ${ }^{1}$

According to a common and widespread diagnosis, Gettier counterexamples will be unavoidable so long as whatever it takes to bridge the gap between true belief and knowledgewarrant, aptness, cognitive achievement, etc.--does not necessary guarantee the truth of the belief in question; naturally enough, so long as whatever bridges the gap between true belief and knowledge does not necessarily guarantee the truth of the given belief, then it will be possible for the belief to meet the conditions for bridging the gap (e.g. for warranted, apt, etc.) while being true

\footnotetext{
${ }^{1}$ The seminal case being Timothy Williamson's non-reductive model in his landmark work, Knowledge and its Limits (2000). Also see Greenough and Pritchard (2009).
} 
for other reasons (i.e. while being Gettiered). Unfortunately, however, if whatever we take to bridge the gap between true belief and knowledge does guarantee the truth of the belief in question, then it is presumably going to be extremely difficult to attain-leaving radical skepticism looming on the immediate horizon. ${ }^{2}$ Advocates of reductive analyses of knowledge face a difficult dilemma: either remain vulnerable to Gettier counterexamples or adopt a view that risks falling into radical skepticism.

Despite this grim diagnosis, many advocates of virtue epistemology-in particular those epistemologists who see knowledge as a kind of success from ability - seem surprisingly sanguine regarding the ability of virtue-theoretic analyses of knowledge to surmount the Gettier Problem. ${ }^{3}$ Some virtue epistemologists, like Ernest Sosa and John Greco, make relatively modest claimsarguing that their respective accounts of knowledge "enables a solution, at least in part, for the Gettier Problem” (Sosa 2007, 42; also see Greco 2010, 13). Others, like John Turri, are bolderclaiming, in no uncertain terms, to have "solved" the Gettier problem (2011). Even recent critics of virtue epistemology seem too optimistic - arguing that various versions of virtue epistemology can indeed "adequately block" Gettier counterexamples but only at the cost of skepticism of comparatively limited scope (Lackey 2009, 34). ${ }^{4}$ In this paper, I argue that the Gettier dilemma facing analyses of knowledge has not been properly appreciated by virtue epistemologist or even virtue epistemology's most vocal critics - that the dilemma facing reductive accounts of knowledge is far more insidious and dire than most virtue epistemologists seem to acknowledge.

In $\S 1$, we will start by considering how recent critics of virtue epistemology seem to understand the Gettier problem facing virtue-theoretic accounts of knowledge. In "Knowledge and Credit" (2009), Jennifer Lackey argues that virtue epistemology faces a dilemma: either solve Gettier cases and be unable to account for testimonial knowledge or account for testimonial knowledge but remain unable to answer the Gettier Problem. In "Knowledge without Credit" (2011), Krist Vaesen argues that virtue epistemology faces a different dilemma: either solve Gettier cases and be unable to account for cases of extended cognition or account for cases of extended cognition but remain unable to answer the Gettier Problem. I will suggest that the dilemma facing the virtuetheoretic analyses of knowledge is more general and more insidious than these critics seem to suggest - that the dilemma isn't between solving Gettier problems and testimonial knowledge, or solving Gettier problems and extended cognition, but rather the dilemma is between solving Gettier problems and widespread, intractable skepticism.

So if the dilemma facing virtue epistemology is far more insidious and general than a dilemma between Gettier counterexamples and testimonial knowledge or a dilemma between Gettier counterexamples and extended cognition, then seemingly some of virtue epistemology's most vocal critics have underestimated the threat facing virtue epistemology. And if the critics have underestimated the threat, then presumably so have virtue epistemology's advocates. In $₫ 2$, I

\footnotetext{
${ }^{2}$ For more on this diagnosis of Gettier Problems, see Zagzebski 1994 and Church 2013 . Elements of this understanding of Gettier counterexamples can also be found in Dretske 1978, Nozick 1981, Chisholm 1982, Goldman 1986, Sturgeon 1993, and Howard-Snyder et al. 2003.

3 For virtue epistemologies that see knowledge as a kind of success from ability, see Sosa 2007; Turri 2011; Greco 2010, 2012.

${ }^{4}$ No doubt, the "limited scope" here is, in Lackey's case, "countless cases" of testimonial knowledge. While that is certainly a tough pill to swallow, the common diagnosis of Gettier counterexamples sketched above is markedly more pessimistic-affecting far more than simply testimonial knowledge. For a similar dilemma regarding extended cognition, see Vaesen 2011.
} 
elucidate the worry that the dilemma facing virtue epistemology is really a dilemma between Gettier counterexamples and radical skepticism. And while I will suggest that the concerns raised by Lackey and Vaesen are perfectly compatible with this more general worry, I will argue that this more general dilemma is where the real challenge to virtue epistemology lies-a challenge that has so far been underappreciated in the contemporary literature.

In $\$ 3$, we will consider how some recent virtue epistemologists have tried to viably defuse the Gettier Problem. After noting the shortcomings of John Turri's bold solution in "Manifest Failure: the Gettier Problem Solved" (2011), we will turn to consider John Greco's recent defense of the knowledge as success from ability hypothesis in "A (Different) Virtue Epistemology" (2012). We will see (i) just how the critiques elucidated in $\$ 1$ have (mis)shaped the dialectic between virtue epistemology and what is required in solving Gettier counterexamples and (ii) how this has lead to virtue epistemologists like Turri and Greco underestimating the widespread insidiousness of Gettier counterexamples. I will argue that not only does Greco's solution to the Gettier Problem fail, it fails precisely along the lines predicted in $\$ 2$ : facing a dilemma between solving Gettier problems and widespread, intractable skepticism.

\section{\$1: Knowledge as Success from Ability, Gettier, and the Critics}

According to number of virtue epistemologists (e.g. Sosa 2007; Turri 2011; Greco 2010; 2012), knowledge is a kind of success from ability. In other words, as Sosa puts it, a given belief is knowledge iff the belief is "true because competent" - belief where the truth is "derive[d] from," "attributable to," or "because [of]" a cognitive competence (Sosa 2007, 23, 33).5 One of the benefits of this account is that it is meant to offer is a viable solution to the Gettier Problem. And given that Gettier cases are quintessentially scenarios where a given belief is true merely by accident or dumb luck (and not because of a cognitive ability), the purported solution is easy enough to see. Consider the following straightforward Gettier case:

FISH CONVENTION: Smith, a novice ichthyologist, is attending a local fish convention. While perusing the various booths and exhibits, he comes to some fish labeled "Cichlasoma dovii," a South American fish known for its aggressive tendencies. Smith then, excited, forms the belief that "there are Cichlasoma dovii at this convention!" Unfortunately, the fish Smith was looking at had been misidentified-they were actually Parachromis managuensis, fish that can easily be mistaken for Cichlasoma dovii. Nevertheless, his belief turns out to be true - in the far corner of the convention building, unbeknownst to Smith, there are real Cichlasoma dovii hidden amidst a very large koi exhibit.

In this case, Smith's belief is formed through an exercise of a cognitive ability, and Smith's belief is true; however, critically, Smith's belief does not hit upon the truth because of the cognitive competence-the success of Smith's belief has nothing to do with his epistemic abilities. Smith's belief is only true by dumb luck; it is true for reasons that his given exercise of epistemic abilities would not have predicted. Understanding knowledge as a kind of success from ability can help us

\footnotetext{
${ }^{5}$ Similar accounts of knowledge of a similar form can be found in Greco 2003; Greco 2007; Greco 2009; Riggs 2002; Sosa 1991, 277; Zagzebski 1996; and Zagzebski 1999.
} 
rightly predict that Smith does not know that "there are Cichlasoma dovii at this fair." And such a solution, it seems, can be easily generalized across all Gettier cases. If knowledge requires beliefs to be true or successful as a result of a epistemic ability, then presumably knowledge will never be wrongly ascribed in a Gettier scenario because Gettier scenarios are (to put it roughly) those cases where a given belief is true because of luck. Virtue epistemology, it seems, has a solution to the Gettier Problem.

This solution has come under scrutiny by a number of critics, predominantly Jennifer Lackey in "Knowledge and Credit" (2009) and Krist Vaesen in "Knowledge without Credit" (2011). Both claim that virtue epistemology's success from ability account of knowledge can solve the Gettier Problem, but only at a cost. The issue, for both Lackey and Vaesen, is making sense of the distinction between (a) having a belief that is both true and produced by ability and (b) having a belief that is true because it is produced from ability. Someone can have a belief that is successful and produced by a cognitive ability and still be vulnerable to Gettier counterexamples; as we saw earlier, Smith, in the case of FISH CONVENTION, has a successful belief that is also produced from an ability - in this case an ability to read signs-but that's obviously not enough to avoid being Gettiered. If knowledge requires a given belief to be true because it is produced from a cognitive ability, where the success comes from the ability, however, other problems seem to arise.

According Lackey, if knowledge requires a belief to be true because it is produced from an ability, then Gettier problems can indeed be avoided; however, knowledge will seemingly be precluded in cases of testimony. Lackey considers the follow scenario:

CHICAGO VISITOR: Having just arrived at the train station in Chicago, Morris wishes to obtain directions to the Sears Tower. He looks around, randomly approaches the first passerby that he sees, and asks how to get to his desired destination. The passerby, who happens to be a Chicago resident who knows the city extraordinarily well, provides Morris with impeccable directions to the Sears Tower. (Lackey 2009, 29)

In this scenario, is the success of Morris's belief attributable to his cognitive abilities? Is his belief true because competent? Seemingly not. As John Greco has noted, "Even if Morris is appropriately attentive to the speaker, and even if his reception of the speaker's testimony is appropriately discriminating, it seems right to say that he forms a true belief because of the speaker's testimony rather than because of his own efforts" $(2012,4)$. As such, it seems like virtue epistemology gives us the wrong result in cases of testimony. Intuitively, Morris knows where the Sears Tower is based on the impeccable directions of the passerby; however, according to the success from ability account of knowledge espoused by many contemporary virtue epistemologies, virtue epistemology seems to wrongfully deny knowledge to Morris, since the success of his belief seems primarily attributable to the passerby's competency rather than his own.

Of course, an advocate of virtue epistemology might be quick to object that, in the case of CHICAGO VISITOR, Morris's cognitive abilities still play an important role in the success of his belief; after all, he wouldn't have known where the Sears Tower was had he not paid close attention. The success of Morris's belief may not be strongly attributable to his cognitive abilities, but it is still attributable to his cognitive abilities in a weaker sense. The problem, however, is that this also seems to be true in Gettier counterexamples. In the case of Fish Convention, Smith's cognitive competencies arguably play an important role in the success of his belief as well; after all, his belief that "there are Cichlasoma dovii at this convention!" would not have been successful had he not 
competently read the sign. Smith's belief seems weakly attributable to his cognitive competencies. As Lackey points out, virtue epistemology faces a dilemma. If we understand the attribution relationship strongly - such that a belief needs to be mostly (if not entirely) true as a result of the given agent's cognitive abilities - then virtue epistemology can avoid Gettier counterexamples like Fish Convention; so understood, however, virtue epistemology will wrongfully preclude knowledge in cases of testimony. Alternatively, if we understand the attribution relation weaklysuch that an agent's cognitive abilities merely need to be a contributing factor in the given belief s success - then virtue epistemology can rightly attribute knowledge in cases of testimony like that in CHICAGO VISITOR; so understood, however, virtue epistemology will remain vulnerable to Gettier counterexamples.

In "Knowledge without Credit" (2011), Krist Vaesen levels a similar dilemma against virtue epistemology regarding extended cognition. Vaesen has us consider a scenario where an airport has recently updated their luggage security scanner. The old luggage scanner, SYSTEM1, simply scanned luggage so as to allow the scanner operator to see what is inside the luggage and detect any dangerous objects. Now, since dangerous objects are exceedingly rare in pieces of luggage, anyone using a SYSTEM1 security scanner will have to "stare for long uninterrupted periods of time at a monitor showing unsuspicious (and boring) goods (like toothbrushes, deodorants, computers, books)" (Vaesen 2011, 523). Such a mind-numbing and tedious task is bound to eventually result in a dramatic decrease in the vigilance of the scanner operator. To combat this, the airport has installed SYSTEM2 luggage scanners, which periodically project "false signals" of dangerous objects onto luggage-scans so as to keep the operator's attention. As Vaesen explains, "Whenever SYSTEM2 projects a false image and the operator notices (she informs the system by, say, clicking on the image), the following message pops up: "False alarm: you were being tested!" If no message appears, the operator knows the threat is real" $(2011,523)$. These false alarms keep the scanner operators alert, and allow them to remain far more vigilant for far longer. Vaeson has us consider the following case:

SISSICASE: Sissi has been a baggage inspector all her life. She used to work with an oldfashioned SYSTEM1, but since 9/11, the airport she is working for introduced a SYSTEM2. Her supervisor Joseph, a cognitive engineer who was actually involved in the design of the device, has informed her how it works (how its operation is almost identical to the operation of the old system). Currently Sissi is inspecting a piece of luggage which contains a bomb. She notices and forms a true belief regarding the contents of the suitcase. As such, the bomb is intercepted and a catastrophe prevented from happening. $(2011,523)$

Intuitively, Sissi knows that the given piece of luggage contains a bomb; however, is her belief true because of a cognitive ability? Seemingly not. As Vaeson explains, "Note...that the relevant counterfactual is Sissi using the old-fashioned SYSTEM1, resulting, we may reasonably suppose, in her failing to notice the bomb, and thus in her forming a false belief (rather than her just failing to form a belief)" $(2011,523)$. In other words, had Sissi been using the SYSTEM1 scanner, her vigilance would have been so low that, chances are, she wouldn't have detected the bomb in question. The success of Sissi's belief seems largely attributable to the SYSTEM2 scanner and not her cognitive abilities. And as such, virtue epistemology seems to wrongly deny that Sissi knows that the piece of luggage before her is bomb-laden.

As before, an advocate of virtue epistemology is free to object that, in the case of SISSICASE, Sissi's cognitive abilities still play an important role in the success of her belief. The success of Sissi's 
belief may not be strongly attributable to her cognitive abilities, but it is still attributable to her cognitive abilities in a weaker sense. And again, the problem is that this also seems to be true in Gettier counterexamples. Virtue epistemology now faces a new but similar dilemma. If we understand the attribution relationship strongly-such that a belief needs to be mostly (if not entirely) true as a result of the given agent's cognitive abilities - then virtue epistemology can avoid Gettier counterexamples like Fish Convention; so understood, however, virtue epistemology will wrongfully preclude knowledge in cases of extended cognition. Alternatively, if we understand the attribution relation weakly_such that an agent's cognitive abilities merely need to be a contributing factor in the given belief s success - then virtue epistemology can rightly attribute knowledge in cases of extended cognition like that in SISSICASE; so understood, however, virtue epistemology will remain vulnerable to Gettier counterexamples.

According to a common and widespread diagnosis, Gettier counterexamples will be unavoidable so long as whatever take to bridge the gap between true belief and knowledgejustification, warrant, aptness, cognitive achievement, etc.-Does not necessary guarantee the truth of the belief in question. This leaves reductive accounts of knowledge with a difficult dilemma: either remain vulnerable to Gettier counterexamples or adopt a view that risks falling into radical skepticism. Tellingly, this is what we are seeing in the virtue epistemology literature. Both Lackey and Vaesen have rightly pointed out that the only way virtue epistemology's success from ability account of knowledge will have any chance at avoiding Gettier counterexamples, is if it is understood very strongly-where a agent's cognitive abilities are not just $a$ contributing factor but the contributing factor to a given belief s success. Insofar as beliefs in Gettier counterexamples are true (at least in part) thanks to luck and not cognitive abilities, such an understanding of virtue epistemology will not be vulnerable to Gettier counterexamples. However, as the dilemma predicts, such a strong account of knowledge faces the threat of skeptical conclusions. And, again, what Lackey and Vaesen have shown us is compatible with this. As they respectively highlighted, if an agent's cognitive abilities need to be the contributing factor to a given belief s success, then virtue epistemology seems to wrongfully preclude knowledge in cases of testimony and extended cognition. In other words, if (a) having a belief that is successful because of a cognitive ability is what bridges the gap between true belief and knowledge and (b) this is strong enough to rule out the possibility of having a belief that is successful for any other reasons (such as epistemic luck), then it will be too strong for knowledge from testimony and extended cognition. If, however, success from ability is weak enough to allow for success for other reasons (such as testimony or extended cognition), then it won't be strong enough to rule out Gettier counterexamples. As Lackey and Vaesen have shown us, virtue epistemology faces a dilemma: either remain vulnerable to Gettier counterexamples or adopt a view that falls into radical skepticism regarding testimony and extended cognition.

The problem, however, is that the dilemma facing virtue epistemology isn't just a dilemma between Gettier counterexamples and skepticism regarding testimony and extended cognition; it is (at least according to the common and widespread diagnosis) a dilemma between Gettier counterexamples and radical skepticism-skepticism regarding testimony, extended cognition, and much more. The problem isn't suppose to be that if success from ability is strong enough to rule out the possibility of having a belief that is successful for any other reasons (such as epistemic luck), then it be too strong for knowledge from testimony and extended cognition; the problem is suppose to be that if success from ability is strong enough to rule out the possibility of having a belief 
that is successful for any other reasons, then it is too strong full stop-wrongfully ruling out knowledge in a wide range of cases. While the dilemmas raised by Lackey and Vaesen are certainly in keeping with this more general worry, the more general worry seemingly has not been fully appreciated. The dilemma facing reductive accounts of virtue epistemology is far more insidious and direr than most virtue epistemologists seem to acknowledge.

\section{\$2: A (Different) Gettier Dilemma}

The general contours of virtue epistemology's purported solution to the Gettier problem should be clear. If knowledge requires having a belief that is successful because of a cognitive ability, then such an account is meant to be immune to Gettier counterexample. How so? Because Gettier counterexamples are meant to be quintessentially scenarios where a given belief is true because of serendipity, dumb luck, or chance-not because of a cognitive ability.

In order to fully appreciate the dilemma facing virtue epistemology we first need to appreciate the fact that being successful due to an ability is a matter of degree. ${ }^{6} \mathrm{~A}$ cognitive ability can be responsible for a given belief being successful to a greater or lesser extent. Just like how an archer's shot can be accurate as a result of her abilities as an archer to a greater or lesser extent, so too can an agent's belief be true as a result of her cognitive abilities to a greater or lesser extent.

Highlighting the idea that success from ability suits degrees (the extent to which a given belief is true because of a cognitive ability) helps us see just what virtue epistemology must demand if it is to rightly handle Gettier counterexamples. Consider the following case:

EXPERT ICHTHYOLOGIST: James is an expert ichthyologist who specializes in freshwater fish; indeed, he is able to competently distinguish between the over 15,000 species of known freshwater fish. James is presented with a freshwater fish and asked to identify its species. Using his amazing skill, he can clearly tell that this particular fish is either going to be a Cichlasoma dovii or a Parachromis managuensis (which can look quite similar), and upon even further expert analysis he comes to the conclusion that it is a Cichlasoma dovii, which it is. However, John, James's nemesis and an expert ichthyologist in his own right, decided the night before to disguise the Cichlasoma dovii to look like a Parachromis managuensis. Thankfully, however, Sheree, James's other expert ichthyologist nemesis (who is conveniently not on speaking terms with John), decided to try to trick James in the same way-arriving shortly after John left, mistakenly perceiving that the fish was a Parachromis managuensis, and disguising John's disguise to make the fish look, once again, like a Cichlasoma dovii. ${ }^{7}$

While James's belief that the given fish is a Cichlasoma dovii is largely true because of his cognitive ability (he was, after all, able to narrow down the possibilities from over 15,000 to just two), he does not ultimately know that the freshwater fish before him is a Cichlasoma dovii since he was

\footnotetext{
${ }^{6}$ This is a point that Ernest Sosa freely admits $(2007,22 n)$.

${ }^{7}$ To be sure, it is worth stressing that Ernest Sosa's distinction between "animal knowledge" and higher-order "reflective knowledge" is not going to come into play here (see Sosa 2007, 23-24). Sosa employs such a distinction to defuse certain Gettier-like cases (e.g. fake barn scenarios); but insofar as he wants to honor the standard intuition that genuine Gettier cases (like EXPERT ICHTHYOLOGIST) genuinely preclude knowledge (both animal and reflective), such a distinction will be of no consequence.
} 
effectively Gettiered by the combined efforts of John and Sheree. As such, if virtue epistemology is to rightly handle such cases, it needs to say that the success of James's belief is not attributable enough to his cognitive abilities - that his competency as an ichthyologist was not responsible for the truth of his belief to a large enough extent. However, strengthened cases could be easily produced. We can easily imagine cases where a given protagonist hits upon a true belief because of an even greater exercise of epistemic competence and ability; so long as that the relevant competency is still fallible it will be possible to create more Gettier cases. As such, it looks like the only way virtue epistemology can fully avoid Gettier counterexamples is if it requires perfect success from ability, if it requires known beliefs to be true entirely because of a given cognitive ability, if it requires the cognitive competence at issue to necessarily guarantee the truth of the belief in question. That, of course, is a tall order! Very few (if any) of even our most epistemically secure beliefs are candidates for being successful entirely because of a cognitive ability. Once success from ability is recognized to suit degrees, virtue epistemology's solution to the Gettier Problem is pushed on the horns of a serious dilemma: either remain vulnerable to strengthened Gettier counterexamples or strengthen the demands of knowledge such that it is almost unattainable, paving the way to radical skepticism. ${ }^{8}$

Of course, while defenders of virtue epistemology may very well grant that success from ability suits degrees, they may want to deny that Gettier cases ever exhibit any. If Gettier cases are simply cases where a given belief is true completely divorced from the respective agent's cognitive abilities, then cases like EXPERT ICHTHYOLOGIST are not really problematic. If a defender of virtue epistemology could show us that the truth of James's belief is (despite appearances) completely divorced from his competencies as a ichthyologist, then we might deny that his belief is knowledge and get the right result, defusing the case and barring any strengthened iterations.

However, that is not a viable defense against EXPERT ICHTHYOLOGIST—surely James's cognitive competencies are partially (if not largely) responsible for his belief hitting upon the truth. Consider the following scenario:

FISH GUESSING: Abbey, Jim, Debbie, and Jeff are playing a guess-the-species-offreshwater-fish game-a game where they are presented with various types of freshwater fish and asked to identify the species. Abbey is an expert ichthyologist. When she is presented with a fish she is able to use her immense skills as a ichthyologist to narrow down the over 15,000 possibilities to the one right answer. Jim too is an expert ichthyologist; indeed, he is every bit as knowledgeable as Abbey. Using his amazing skill, he can clearly tell that the fish before him is either going to be a Cichlasoma dovii or a Parachromis managuensis (which can look quite similar), and upon even further expert analysis he comes to the conclusion that it is a Cichlasoma dovii, which it is. However, after narrowing down the over 15,000 possibilities to just Cichlasoma dovii or a Parachromis managuensis, Jim is Gettiered about these final two options. Thirdly, Debbie is presented with a fish. She knows almost nothing about ichthyology; however, she is a savant-having memorized the names of every single species of freshwater fish. She has no idea what species is before her, so she simply picks a species at random and just happens to get it right. Finally,

\footnotetext{
${ }^{8}$ In "Getting 'Lucky' with Gettier" (2013), Ian Church analyzes the nature of luck in terms of degrees so as to lend credence to Linda Zagzebski's (1994) diagnosis of Gettier problems as inescapable. According to Church, even a minute degree of luck (of the relevant sort) can preclude knowledge. If Church is correct, degrees of luck will seemingly map onto degrees of aptness, thus offering explanatory power for the thesis proposed in this paper.
} 
Jeff is presented with a fish. He knows absolutely nothing about ichthyology. He doesn't even know the names of any species. When he goes to hazard a guess; however, he chokes on a burp and just so happens to utter the name of the species before him.

In this scenario, it is easy to assume that Abbey's belief is largely true because of her cognitive abilities - she is, after all, an expert ichthyologist and is able to identify the fish as a direct result of this expertise. Secondly, I think we can also easily assume that Debbie's belief is marginally true as a result of her cognitive abilities (though the success of her belief is certainly no where near attributable enough to her cognitive abilities to constitute knowledge) — after all, at least she knows the names of the various species of freshwater fish. And thirdly, I think we can safely assume that Jeff s correct answer is in no way a reflection of his cognitive abilities-Jeff s correct answer is well and truly devoid of success from ability. What about Jim? To say that Jim (who's circumstances are just like James's in the case of EXPERT ICHTHYOLOGIST) has a belief that is in no way true as a result of his cognitive abilities is to put it on par with Jeffs choked-on burp. But that is surely wrong. Surely, the cognitive abilities of Jim (and James) are largely responsible for the truth of their belief; even though he was eventually Gettiered in the very end, his cognitive abilities surely brought him most of the way there. The dilemma facing virtue epistemology between Gettier counterexamples and skepticism still stands.

In $₫ 1$, we saw how recent critics of virtue epistemology understand the Gettier problem facing virtue-theoretic accounts of knowledge. According to Jennifer Lackey, virtue epistemology faces a dilemma: either solve Gettier cases and be unable to account for testimonial knowledge or account for testimonial knowledge but remain unable to answer the Gettier Problem. According to Krist Vaesen, virtue epistemology faces a different (though similar) dilemma: either solve Gettier cases and be unable to account for cases of extended cognition or account for cases of extended cognition but remain unable to answer the Gettier Problem. What we've now seen, however, is that a third, more general dilemma is lurking in the neighborhood. Perhaps, the dilemma facing the virtuetheoretic analyses of knowledge isn't just between solving Gettier problems and testimonial knowledge, or solving Gettier problems and extended cognition-as the critiques in $\$ 1$ suggested-but perhaps the dilemma is between solving Gettier problems and widespread, intractable skepticism.

\section{\$3: Applying the Dilemma}

Why does it matter whether or not we see the threat facing virtue epistemology as a dilemma between Gettier counterexamples and testimonial knowledge, or as a dilemma between Gettier counterexamples and extended cognition, or (as I suggested in \$2) a dilemma between Gettier counterexamples and radical skepticism? It matters insofar as how the threat is perceived will affect the shape of proposed solutions. To put it roughly, if the threat facing virtue epistemology is perceived to have a relatively limited scope (e.g. cases of testimony or cases of extended cognition), then any proposed solutions will be likely to correspondingly limited. If the threat facing virtue epistemology is perceived to have an extremely broad scope (e.g. most instances of knowledge), however, then any proposed solutions will be like to be correspondingly broad and seemingly far more dramatic. 
In any case, despite the grim diagnosis explicated in $\$ 2$, many virtue epistemologists have been optimistic about virtue epistemology's ability to provide a viable solution to the Gettier Problem. The most striking example of this optimism has been John Turri's brazen claim to a solution in "Manifest Failure: The Gettier Problem Solved" (2011). Turri used an account of manifestation not only to improve upon many seminal projects within contemporary epistemology but also to solve the Gettier Problem. This latter result, of course, is quite striking. For nearly 50 years, epistemologists have been chasing a solution for the Gettier Problem but with little to no success. If Turri was right, if he actually solved the Gettier Problem, then he would have done something that is absolutely groundbreaking and really quite remarkable. Unfortunately, as I've pointed out elsewhere (CITATION REMOVED), Turri's proposal fails for precisely the reasons I highlighted in $\$ 2$.

But while one purported, virtue-theoretic solution to the Gettier Problem flounders, another emerges. In "A (Different) Virtue Epistemology” (2012), John Greco proposes his own solution to the Gettier Problem. According to Greco, the idea that knowledge is a kind of success from ability seems to have "surprising theoretical power," particularly with it comes to diagnosing the Gettier Problem (2012, 2). As Greco explains:

"In Gettier cases, $S$ 's belief is true and S's belief is competent, but $S$ 's belief is not true because competent. That is, $S$ does not have a true belief because $S$ 's belief is produced by ability...In cases of knowledge, true belief is no mere lucky success; rather, $S$ 's believing the truth is attributable to the exercise of ability. Put differently: Knowledge is an achievement in a sense that lucky guesses (and the like) are not. $(2012,2)$

Again, if knowledge requires beliefs to be true or successful as a result of a epistemic ability, then presumably knowledge will never be wrongly ascribed in a Gettier scenario because Gettier scenarios are (to put it roughly) those cases where a given belief is true because of luck.

As we saw in $\$ 1$, however, Lackey and Vaesen have pointed out that the only way virtue epistemology's success from ability account of knowledge will have any chance at avoiding Gettier counterexamples, is if it is understood very strongly - where a agent's cognitive abilities are not just a contributing factor but the contributing factor to a given belief s success. Insofar as beliefs in Gettier counterexamples are true (at least in part) thanks to luck and not cognitive abilities, such an understanding of virtue epistemology will not be vulnerable to Gettier counterexamples. However, as Lackey and Vaesen have shown us, if an agent's cognitive abilities need to be the contributing factor to a given beliefs success, then virtue epistemology seems to wrongfully preclude knowledge in cases of testimony and extended cognition. In other words, if (a) having a belief that is successful because of a cognitive ability is what bridges the gap between true belief and knowledge and (b) this is strong enough to rule out the possibility of having a belief that is successful for any other reasons (such as epistemic luck), then it will be too strong for knowledge from testimony and extended cognition.

And while $\$ 2$ suggested that such dilemmas are mere symptoms of a broader threat to virtue epistemology, the respective dilemmas of Lackey and Vaesen have been the guiding lights in reshaping virtue epistemology's response to the Gettier Problem. This can be most clearly seen in Greco's work in "A (Different) Virtue Epistemology" (2012). In response to the respective dilemmas posed by Lackey and Vaesen, Greco argues that the success from ability account of knowledge should be understood such that "A success is attributable to S's ability just in case S's 
ability contributes to that success in the right way" by which he means "in a way that would regularly serve relevant purposes"(2012, 14). Greco has us consider the following scenario:

SOCCER: Playing in a soccer game, Ted receives a brilliant, almost impossible pass. With the defense out of position and the goalie lying prostrate on the ground, Ted kicks the ball into the net for an easy goal...Compare this case with another: Ted is playing in a soccer game, but not paying attention. Never seeing the ball, a brilliant pass bounces off his head and into the goal. Here Ted does not deserve credit for the goal. He was involved in a way, but not in the right sort of way. $(2012,14-15)^{9}$

In the dilemmas posed by Lackey and Vaesen, the question for virtue epistemology was whether or not agent's cognitive abilities are just $a$ contributing factor or the contributing factor to a given belief s success. Lackey and Vaesen seem to view the role of cognitive abilities play in a given beliefs success as quantitative-concerned primarily with the extent to which a given belief is successful because of a cognitive competence. If cognitive abilities only need to be partially responsible for the belief s success, then virtue epistemology will be vulnerable to Gettier counterexamples; if cognitive abilities need to be entirely responsible for a beliefs success, however, then virtue epistemology seems to wrongly preclude knowledge in cases of testimony and extended cognition. This quantitative understanding of the role of cognitive abilities, according to Greco, is misguided. Even though Ted's contribution to the scored goal (in the first instance) was extremely minimal, he still deserves credit because his contribution was of the sort (i.e. the right sort of quality) that deserves credit. Likewise, even though contribution of the protagonists' respective cognitive abilities in CHICAGO VISITOR and SISSICASE are minimal, they still acquire knowledge because their cognitive abilities' contributions were of the right sort (i.e. the right sort of quality); the cognitive abilities of the protagonists contributed to the success of their respective beliefs "in the right way" - "in a way that would regularly serve relevant purposes"(Greco 2012, 14).

Greco's understanding of knowledge as success from ability-where the beliefs success is attributable to the relevant cognitive abilities if those abilities contributed to the success in the right way-seems to rightly prescribe knowledge in cases of testimony and extended cognition; what is more, it seems to have no problem defusing garden-variety Gettier cases-Gettier cases like FISH CONVENTION. As Greco explains:

In cases of testimonial knowledge and knowledge involving extended cognition, but not in Gettier cases, S's believing from ability contributes to $S$ 's believing the truth in the right way-i.e., in a way that would regularly serve relevant informational needs. That is, in cases of knowledge, $S$ 's abilities exploit social practices and technologies so as to produce true belief in regular, dependable ways. In Gettier cases that does not happen. S ends up with a true belief, and $S^{\prime}$ s abilities even contribute to that, but not in a way that can be regularly exploited, not in a way that is dependable or reliable... In all of the cases, S's believing from ability contributes to $S$ 's ending with a true belief-in all of the cases, the exercise of ability is part of the total causal structure leading up to the desired effect. But in Gettier cases the route... is not the sort of route that could be regularly exploited for relevant purposes. $(2012,17)$

\footnotetext{
${ }^{9}$ These cases can originally be found in Greco 2010, 82-83.
} 
Greco, it seems, has given us an account of success from ability that can rightly handle cases of testimony without making it vulnerable to Gettier counterexamples. What is more, it seems like he has given an account of success from ability that handle cases of extended cognition without making it vulnerable to Gettier counterexamples. The dilemmas posed by Lackey and Vaesen respectively seem to be defused.

But what about the dilemma sketched in $\$ 2$ ? I have suggested that the dilemmas posed by Lackey and Vaesen are merely symptoms of a broader threat facing virtue epistemology. If this is right, then perhaps any success against Gettier counterexamples afforded by Greco's understanding of success from ability - where the belief's success is attributable to the relevant cognitive abilities if those abilities contributed to the success in the right way-is merely fleeting, perhaps strengthened counterexamples are around the corner. ${ }^{10}$ In the rest of this section, I argue that Greco's virtue epistemology-one the most seminal virtue-theoretic account of knowledge in the contemporary literature-fails to viably surmount the Gettier Problem: failing precisely along the lines predicted in $\$ 2$, facing a dilemma between remaining vulnerable to strengthened Gettier counterexamples or strengthening the demands of knowledge such that it is almost unattainable, paving the way to radical skepticism.

The first point to note is that success from ability-even in cases where the success is attributable to the ability in the right way-is a matter of degree. Let's revisit Greco's soccer analogy. Consider the following three cases:

TED1: Playing in a soccer game, Ted receives a brilliant, almost impossible pass. With the defense out of position and the goalie lying prostrate on the ground, Ted kicks the ball into the net for an easy goal. $(2012,14-15)^{11}$

TED2: Playing in a soccer game, Ted receives an excellent pass. With most of the defense out of position, Ted out maneuvers a final defender and is able to fire the ball past the goalie and into the net for an impressive goal.

TED3: Playing in a soccer game, Ted steals the ball from an opposing player and singlehandedly runs it down the field. Ted outmaneuvers every defender and fires the ball past the goalie and into the net for a magnificent, indeed awe-inspiring, goal.

In all three cases, Ted's success in scoring the goal is attributable to his abilities, because his abilities were involved in the right way-in the sort of way that deserves credit. That said, however, the amount of credit Ted deserves - the extent to which his abilities are responsible for the successful goal-varies from case to case. In TED1, Ted deserves credit, sure enough, but relatively little

\footnotetext{
${ }^{10}$ And this is in keeping with a body of literature that suggests that virtue-theoretic proposals (like Greco's) are ultimately going to be unable to viably surmount the Gettier Problem - see Pritchard 2003; Pritchard 2005, chap. 7; Pritchard 2007; Pritchard, Millar, and Haddock 2010, chap. 3; Kallestrup and Pritchard 2012. But what is more, it is keeping with the growing pessimism regarding the possibility of any reductive account of knowledge (virtuetheoretic or otherwise) viably surmounting the Gettier Problem - see Williamson 2000; Floridi 2004; Church 2013. ${ }^{11}$ These cases can originally be found in Greco 2010, 82-83.
} 
credit because Ted's contribution to the scored goal was minimal. In TED2, Ted seemingly deserves more credit, because his contribution to the scored goal was more significant. And finally, in TED 3, Ted seemingly deserves even more credit, because he was singlehandedly responsible for the goal's success. In all three cases, Ted deserves credit-the successful goal is attributable to Ted's abilities in such a way that deserves credit-however, the amount of credit varies from case to case.

And as such, the second point to note is that Greco's shift from a quantitative understanding of the role cognitive abilities apply in a given belief s success (against environmental features like reliable informants and helpful technology) to a qualitative understanding, does not mean the claim that success from ability admits degrees - a central claim of the dilemma posed in $\$ 2$-is now moot. Since the respective dilemmas posed by Lackey and Vaesen turn on whether or not an agent's cognitive abilities are just $a$ contributing factor or the contributing factor to a given belief s success, Greco's shift to a focus on the quality of the cognitive ability's contribution defused those dilemmas; however, the dilemma posed in $\$ 2$ turns on success from ability admitting degrees, whatever the quality. So long as what bridges the gap between true belief and knowledge admits degrees-whether it is success form ability where the ability contributes in the right way, or whether it is a cognitive ability with the help of a reliable informant, or a cognitive ability with the help of technology—the dilemma posed in $\$ 2$ remains intact.

Highlighting these two points helps us see just what Greco's virtue epistemology must demand if it is to rightly handle Gettier counterexamples. Recall the EXPERT ICHTHYOLOGIST Gettier case. Greco is going to want to know whether or not the success of James's belief is attributable to his cognitive abilities in the right way- "in a way that would regularly serve relevant purposes," "in a way that would regularly serve relevant informational needs" (Greco 2012, 14, 17). But it seems clear that the success of James's belief is largely attributable to his cognitive abilities in the right way, in a way that would meet the relevant purposes and would serve relevant informational needs. James's expertise with freshwater fish is immense, and his ability to narrow down the over 15,000 possibilities was almost flawless; it'd be difficult to find someone who could satisfy the relevant informational needs any better! As such, if Greco's virtue epistemology is to rightly handle such cases, it needs to say that the success of James's belief is not attributable enough to his cognitive abilities-that his competency as an ichthyologist was not responsible for the truth of his belief (in the right way) to a large enough extent. However, strengthened cases could be easily produced. We can easily imagine cases where a given protagonist hits upon a true belief because of an even greater exercise of epistemic competence and ability, where the success of their belief is even more attributable to their cognitive competencies; so long as that the relevant competency is still fallible it will be possible to create more Gettier cases. As such, it looks like the only way Greco's virtue epistemology can fully avoid Gettier counterexamples is if it requires perfect success from ability, if it requires known beliefs to be true entirely because of a given cognitive ability (and in the right way), if it requires the cognitive competency at issue to necessarily guarantee the truth of the belief in question. That, of course, is a tall order! Very few (if any) of even our most epistemically secure beliefs are candidates for perfect success from ability, where the success of the belief is entirely attributable to our cognitive abilities in the right way. Once Greco's understanding of success from ability is recognized to suit degrees, his solution to the Gettier Problem is pushed on the horns of the same dilemma explicated in \$2: either remain vulnerable to strengthened Gettier counterexamples or strengthen the demands of knowledge such that it is almost unattainable, paving the way to radical skepticism. 
Now, a defender of Greco's virtue epistemology may very well grant that success from ability suits degrees - that the success of a belief can be attributable to a given cognitive competency in the right way to a greater or lesser extent-however, they may want to deny that Gettier cases ever exhibit any. If Gettier cases are simply cases where a given belief is true completely divorced from the respective agent's cognitive abilities, then cases like EXPERT ICHTHYOLOGIST are not really problematic. If a defender of virtue epistemology could show us that the truth of James's belief is (despite appearances) completely divorced from his competencies as a ichthyologist, then we might deny that his belief is knowledge and get the right result, defusing the case and barring any strengthened iterations.

However, just like we saw in $\$ 2$, that is not a viable defense against EXPERT ICHTHYOLOGIST - surely James's cognitive competencies are partially (if not largely) responsible for his belief hitting upon the truth, surely the success of James's belief is partially (if not largely) attributable to his cognitive abilities in the right way. Recall the case of FISH GUESSING. In that scenario, it is easy to assume that Abbey's belief is largely true because of her cognitive abilities - she is, after all, an expert ichthyologist and is able to identify the fish as a direct result of this expertise. Like Ted in TED3, the success of her belief is almost entirely attributable to her abilities in the right way. Secondly, I think we can also easily assume that Debbie's belief is marginally true as a result of her cognitive abilities (though the success of her belief is certainly no where near attributable enough to her cognitive abilities to constitute knowledge) - after all, at least she knows the names of the various species of freshwater fish. Somewhat like TED1, the success of Debbie's belief is attributable to her abilities in the right way to some minimal extent. And thirdly, I think we can safely assume that Jeff s correct answer is in no way a reflection of his cognitive abilities-Jeff s correct answer is well and truly devoid of success from ability. In no way, is Jeff s correct answer attributable to his cognitive abilities, let alone attributable to his cognitive abilities in the right way. What about Jim? To say that Jim (who's circumstances are just like James's in the case of EXPERT ICHTHYOLOGIST ) has a belief that is in no way true as a result of his cognitive abilities is, like we saw in $\$ 2$, to put it on par with Jeff s choked-on burp. But, again, that is surely wrong. Surely, the cognitive abilities of Jim (and James) are largely responsible for the truth of their belief were the success of their belief is largely attributable to their respective cognitive competencies in such a "that would regularly serve relevant purposes," in a way "that would regularly serve relevant informational needs" (Greco 2012, 14, 17). Even though they were eventually Gettiered in the very end, their cognitive abilities surely brought him most of the way there, and got them there in the right way. The dilemma leveled against Greco's virtue epistemology still stands. And as such, even if Greco's account of knowledge can dissolve the respective dilemmas of Lackey and Vaesen, a far more insidious and far-reaching dilemma remains unresolved, the dilemma explicated in $\$ 2$, the dilemma between solving Gettier problems and widespread, intractable skepticism.

\section{Conclusion}

According to a widespread and common diagnosis of the Gettier Problem, any reductive account of knowledge will face a dilemma: either remain vulnerable to Gettier counterexamples or strengthen the demands of knowledge such that it is almost unattainable, paving the way to radical skepticism. Epistemologists have wrestled with the Gettier Problem for 50 years, and the light of experience has vindicated both horns of this dilemma time and time again. Despite this grim 
history, most virtue epistemologists, however, have remained optimistic. In this paper, I suggested that this is, in part, because the full breadth of the problem facing virtue-theoretic analyses of knowledge has not yet been fully appreciated.

Jennifer Lackey and Krist Vaesen have developed excellent critiques of virtue epistemologyarguing that the only way the virtue-theoretic success form ability account can viably avoid Gettier counterexamples is if they wrongfully preclude knowledge in cases of testimony and extended cognition, respectively-however, the dilemmas they pose are localized manifestations of a broader issue. And this matters insofar as how the threat is perceived by virtue epistemologists will effect their proposed solutions.

In this paper, I have argued that the Gettier dilemma facing analyses of knowledge has not been properly appreciated by virtue epistemologist or even virtue epistemology's most vocal criticsthat the dilemma facing reductive accounts of knowledge is far more insidious and direr than most virtue epistemologists seem to acknowledge. I elucidated how the threat posed by Gettier counterexamples to virtue epistemology has been perceived in the literature: as a dilemma between either Gettier counterexamples and testimonial knowledge or Gettier counterexamples and extended cognition. And I suggested that-in light of the a common diagnosis - the dilemma facing virtue epistemology is quite a bit broader: a dilemma between Gettier counterexamples and radical skepticism. Finally, I argued that the recent accounts of virtue epistemology that aim to dissolve the dilemmas elucidated in $\$ 1$, seemingly lack the resources for addressing the more general threat highlighted in $\$ 2$. Once this more threat is appreciated, it seems contemporary virtue epistemology is in a very difficult position: either remain vulnerable to Gettier counterexamples or strengthen the demands of knowledge such that it is almost unattainable, paving the way to radical skepticism.

\section{References}

Chisholm, Roderick M. 1982. The Foundations of Knowing. Brighton, UK: The Harvester Press. Church, Ian M. 2013. "Getting 'Lucky' with Gettier." European Journal of Philosophy 21, no. 1: $37-49$.

Dretske, Fred I. 1978. "Conclusive Reasons." In Essays on Knowledge and Justification, edited by George Sotiros Pappas and Marshall Swain. Cornell University Press.

Floridi, L. 2004. "On the Logical Unsolvability of the Gettier Problem.” Synthese 142, no. 1: 6179.

Gettier, Edmund. 1963. "Is Justified True Belief Knowledge?” Analysis 23: 121-23.

Goldman, Alvin I. 1986. Epistemology and Cognition. Harvard University Press.

Greco, John. 2003. “Knowledge as Credit for True Belief.” In Intellectual Virtue: Perspectives From Ethics and Epistemology, edited by Michael DePaul and Linda Zagzebski, 111-34. Oxford: Oxford University Press.

_- - 2007. "The Nature of Ability and the Purpose of Knowledge." Philosophical Issues 17, no. 1:57-69.

- - 2009. "Knowledge and Success from Ability." Philosophical Studies 142, no. 1: 17-26.

- - 2010. Achieving Knowledge: A Virtue-Theoretic Account of Epistemic Normativity. Cambridge University Press. 
- - . 2012. "A (Different) Virtue Epistemology." Philosophy and Phenomenological Research 85, no. 1: 1-26.

Greenough, Patrick, and D. Pritchard. 2009. Williamson on Knowledge. Oxford, UK: Oxford University Press.

Howard-Snyder, Daniel, F. Howard-Snyder, and N. Feit. 2003. "Infallibilism and Gettier's Legacy." Philosophy and Phenomenological Research 66, no. 2: 304-27.

Kallestrup, Jesper, and D. Pritchard. 2012. "Virtue Epistemology and Epistemic Twin Earth." European Journal of Philosophy, n/a-n/a. doi:10.1111/j.1468-0378.2011.00495.x.

Lackey, Jennifer. 2009. “Knowledge and Credit." Philosophical Studies 142, no. : 27 - 42. Nozick, Robert. 1981. Philosophical Explanations. Oxford, UK: Oxford University Press. Pritchard, Duncan. 2003. "Virtue Epistemology and Epistemic Luck." Metaphilosophy 34, no. 1/2: 106-30.

- - . 2005. Epistemic Luck. Oxford, UK: Oxford University Press.

- - . 2007. "Anti-Luck Epistemology." Synthese 158: 277-97.

Pritchard, Duncan, A. Millar, and A. Haddock. 2010. The Nature and Value of Knowledge: Three Investigations. Oxford, UK: Oxford University Press.

Riggs, Wayne D. 2002. "Reliability and the Value of Knowledge." Philosophy and Phenomenological Research 64, no. 1:79-96.

Sosa, Ernest. 1991. Knowledge in Perspective: Selected Essays in Epistemology. Cambridge University Press.

- - . 2007. A Virtue Epistemology: Apt Belief and Reflective Knowledge. Oxford, UK: Oxford University Press.

Sturgeon, Scott. 1993. "The Gettier Problem." Analysis 53 (3): 156-64.

Turri, John. 2011. "Manifest Failure: The Gettier Problem Solved." Philosophers' Imprint 11 (8).

Vaesen, Krist. 2011. "Knowledge Without Credit, Exhibit 4: Extended Cognition." Synthese 181 (515): 515-29.

Williamson, Timothy. 2000. Knowledge and Its Limits. Oxford, UK: Oxford University Press.

Zagzebski, Linda. 1994. “The Inescapability of Gettier Problems." The Philosophical Quarterly 44: 65-73.

- - . 1996. Virtues of the Mind: An Inquiry into the Nature of Virtue and the Ethical Foundations of Knowledge. Cambridge: Cambridge University Press.

- - . 1999. "What is Knowledge?" In The Blackwell Guide to Epistemology, edited by Ernest Sosa and John Greco. Oxford, UK: Blackwell Publishing. 